Marloes L.C. Hagemans

Sabine P.M. van Schie

A. Cecile J.W. Janssens

Pieter A. van Doorn

Arnold J.J. Reuser

Ans T. van der Ploeg

\title{
Fatigue: an important feature of late-onset Pompe disease
}

Abstract Objective To investigate the prevalence and severity of fatigue in adult patients with Pompe disease. Methods The Fatigue Severity Scale (FSS) was assessed in an international population of 225 adults with Pompe disease, a metabolic disorder presenting as a slowly progressive proximal myopathy. The FSS scores were compared to those of healthy controls and the relationship between the level of fatigue and other patient characteristics was investigated. Results The mean age of the participants was 47 (SD 13) years and the mean disease duration 11 (SD 8) years. $43 \%$ used a wheelchair and $46 \%$ had respiratory support, $29 \%$ needed both. $67 \%$ of the participants had a FSS score $\geq 5$, indicating severe fatigue. The mean FSS score was 5.2 (SD 1.5), which was significantly higher than that of healthy controls $(p<0.001)$. Fatigue was not related to age, sex or disease duration. Patients who used a wheelchair or respiratory support were on average more fatigued than those who did not $(p=0.01)$. However, of the patients who did not use these aids, $59 \%$ also had a FSS score $\geq 5$. FSS scores were highest among patients who reported a high frequency of sleep disorders, but patients who never experienced sleep difficulties were also fatigued (mean FSS score $=4.8)$. Conclusion Fatigue is highly prevalent among both mildly and severely affected adult patients with Pompe disease. The FSS appears a useful tool in assessing fatigue in Pompe disease.

Key words Pompe disease . alpha-glucosidase · lysosomal storage disorder myopathy $\cdot$ Fatigue Severity Scale

\section{Introduction}

Pompe disease (Glycogen Storage Disease type II, acid maltase deficiency) is an autosomal recessive disorder caused by deficiency of the enzyme acid $\alpha$-glucosidase. As a result of this deficiency, lysosomal glycogen cannot be degraded and accumulates in the lysosomes of virtually all body tissues $[7,16]$. This leads to a broad clinical spectrum ranging from a severe, classic infantile phenotype with generalized muscle weakness, a hypertrophic cardiomyopathy and death usually before the first year of life [28] to a slowly 
progressive proximal myopathy without involvement of the heart. Patients on this end of the spectrum are described as having 'late-onset' $[12,21]$ or 'nonclassic' [31] Pompe disease and may present at any age, sometimes as late as the sixth decade of life. Eventually they may become wheelchair-bound and dependent on artificial ventilation $[7,16]$.

Besides symptoms related to weakness of the skeletal and respiratory muscles, non-motor problems such as fatigue can also have a profound and disabling impact on the patients' lives. Fatigue is difficult to define, as it is often a non-specific and subjective complaint. Two suggested definitions are 'extreme and persistent tiredness, weakness or exhaustionmental, physical or both' [6] and 'difficulty in initiation of or sustaining voluntary activities' [3]. Although fatigue is a frequent symptom in many chronic disorders, it has received little attention in Pompe disease and was only sporadically reported [4, $20,23,27,32]$. In a recent study on the clinical condition of late-onset Pompe patients we found that $76 \%$ of the study population reported symptoms of fatigue and that fatigue was among the first complaints for $24 \%$ [12]. In the present study, we investigated the prevalence and severity of fatigue in more detail in a large, international group of adult patients with Pompe disease and studied the associations between fatigue and several other patient characteristics.

\section{Methods}

\section{Patients and procedures}

Data were obtained between May 2002 and January 2004 as part of an ongoing international study on the natural course of Pompe disease in children and adults [11-13]. The medical ethical committee of Erasmus MC approved the project and the participants provided informed consent. Patients were recruited through patient organisations affiliated with the International Pompe Association (IPA). Participants were asked to complete a booklet of questionnaires, including one on fatigue for the patients of 18 years and older. The levels of fatigue in our study population were compared to those of healthy controls that were described previously in a study on immune-mediated polyneuropathies. This comparison group consisted of 113 healthy persons, $48 \%$ female, with a mean age of 54 (SD 15) years [22].

\section{Fatigue assessment}

The severity and impact of fatigue was assessed using the Fatigue Severity Scale (FSS) [19]. The total FSS score is the average of the 9 item scores and ranges from 1 ('no signs of fatigue') to 7 ('most disabling fatigue'). Scores of 4 and higher indicate that patients are suffering from fatigue and scores of 5 and higher that patients are suffering from severe fatigue $[9,15,22]$. We used the validated English and Dutch translations of the FSS [19, 22], and a German version that was translated by a certified translator. The FSS has demonstrated good internal consistency, reliability and validity in studies among patients with multiple sclerosis, immune-mediated polyneuropathies and chronic hepatitis $C[18,19,22]$ and is easy to complete. In the present study, individual item scores were missing for only $4 \%$ of the study population; the maximum number of missing items per patient was 3 . When individual item scores were missing, the FSS score was calculated with the remaining items.

\section{Other information}

Additional information was gathered on date of birth, year of diagnosis, sex, use of wheelchair or walking aids, use of respiratory support, number of hours respiratory support per day, and presence of sleep disorders as indicated by the patient ('never', 'occasionally', or 'often'). Disease duration was calculated as the time between diagnosis and questionnaire completion.

\section{Statistical analyses}

Differences between countries in age, age at diagnosis, disease duration and FSS score (UK, USA, The Netherlands and Germany) were tested using one-way analysis of variance (ANOVA) and in sex, wheelchair use and use of respiratory support by $\chi^{2}$ tests. Mean scores of our study population were compared to the scores of healthy controls by calculating the $t$ ratio using the published mean and standard deviation $[14,22]$. Internal consistency was evaluated with Cronbach's alpha coefficient and test-retest reliability with the intraclass correlation coefficient [24]. The test-retest reliability was determined in a subgroup of 34 Dutch patients who completed the FSS twice, with approximately 1 month between both measurements. The relation between FSS score and age, disease duration and number of hours ventilation per day was evaluated with Spearman's rank correlation coefficient.

Differences in mean FSS score between groups based on wheelchair and ventilator use and on the self-reported frequency of sleep disorders were tested with ANOVA. All analyses were performed using SPSS for Windows (version 11.5). A p-value of $\leq 0.05$ was considered statistically significant.

\section{Results}

\section{Patient characteristics}

A total of 225 patients of 18 years and older completed the FSS. The mean age of the study population was 47 (SD 13) years and 54\% were women. The mean disease duration was 11 (SD 8) years. Forty-three percent used a wheelchair and $46 \%$ used respiratory support, $29 \%$ needed both. The study population included patients from the USA $(n=75)$, the Netherlands $(n=50)$, Germany $(n=50)$, the UK $(n=17)$, Australia $(n=13)$, Canada $(n=8)$, Austria $(n=3)$, Switzerland $(n=2)$, Belgium, Denmark, Italy, Luxembourg, Spain, New Zealand and Taiwan (all $\mathrm{n}=1$ ). No statistically significant differences in patient characteristics between the countries were found.

\section{FSS scores}

The mean FSS score of the study population was 5.2 (SD 1.5). $78 \%$ of the patients had a FSS score of 4 or higher ('fatigued') and $67 \%$ a FSS score of 5 or higher 
Table 1 Means and distribution of Fatigue Severity Scale item scores of 225 adult patients with Pompe disease

\begin{tabular}{|c|c|c|c|c|}
\hline \multirow[b]{2}{*}{ Item } & \multirow[b]{2}{*}{ Mean } & \multicolumn{3}{|c|}{$\begin{array}{l}\text { Score } \\
\text { distribution } \\
(\%)\end{array}$} \\
\hline & & $1-3$ & 4 & $5-7$ \\
\hline My motivation is lower when I am fatigued & 5.7 & 9 & 3 & 88 \\
\hline Exercise brings on my fatigue & 5.7 & 10 & 6 & 84 \\
\hline Fatigue interferes with my physical functioning & 5.5 & 14 & 5 & 81 \\
\hline My fatigue prevents sustained physical functioning & 5.4 & 18 & 6 & 76 \\
\hline I am easily fatigued & 5.3 & 16 & 9 & 75 \\
\hline $\begin{array}{l}\text { Fatigue interferes with carrying out certain } \\
\text { duties and responsibilities }\end{array}$ & 5.0 & 23 & 7 & 70 \\
\hline $\begin{array}{l}\text { Fatigue interferes with my work, family, } \\
\text { or social life }\end{array}$ & 4.9 & 24 & 9 & 67 \\
\hline $\begin{array}{l}\text { Fatigue is among my three most } \\
\text { disabling symptoms }\end{array}$ & 4.8 & 29 & 6 & 65 \\
\hline Fatigue causes frequent problems for me & 4.8 & 26 & 11 & 63 \\
\hline
\end{tabular}

Item scores range from 1 (strongly disagree) to 7 (strongly agree). The items are ranked by descending mean item score

('severely fatigued'). The distributions of item scores are presented in Table 1 . Items on which $75 \%$ or more of the patients scored 5 or higher were mainly related to physical functioning: 'my fatigue prevents sustained physical functioning', 'fatigue interferes with my physical functioning' and 'exercise brings on my fatigue'. $65 \%$ of the patients classified fatigue among their three most disabling symptoms.

The mean FSS score of our study population was significantly higher than the score of healthy controls (mean FSS score 2.9, p < 0.001). Although the mean FSS score of the German Pompe patients was lower than the scores of patients from the UK, USA and the Netherlands (Fig. 1), it was still significantly higher than that of the Dutch healthy controls $(p<0.001)$. The FSS showed excellent internal consistency in our international study population (Cronbach's alpha $=0.92$ for the Dutch version and 0.94 for the English and German versions) and good 1-month test-retest reliability in the Dutch subgroup (intraclass correlation coefficient $=0.86$ ).

\section{Relationship between fatigue and patient charac- teristics}

FSS scores were not related to sex $(p=0.26)$, age or disease duration $(\mathrm{r}=-0.05$ and $-0.03, \mathrm{p}>0.47)$. Figure 2 shows the FSS score in groups based on wheelchair and ventilator use. When tested in four groups, no significant differences in FSS score were found, but patients who did not use a wheelchair or respiratory support were less fatigued than those who used one or both of these aids (FSS score $=4.9$ vs. 5.4 , $p=0.01)$. However, even in the group of patients who did not use a wheelchair or respiratory support, $71 \%$

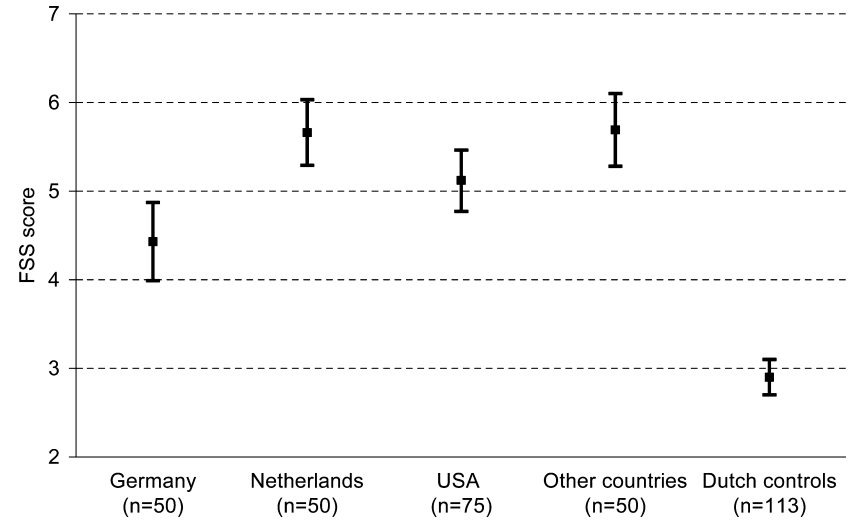

Fig. 1 Mean scores $(95 \% \mathrm{Cl})$ on the Fatigue Severity Scale of adult patients with Pompe disease from different countries. FSS scores differed significantly between countries when tested with ANOVA $(p<0.001)$. Scores of healthy controls were obtained from the literature [22]

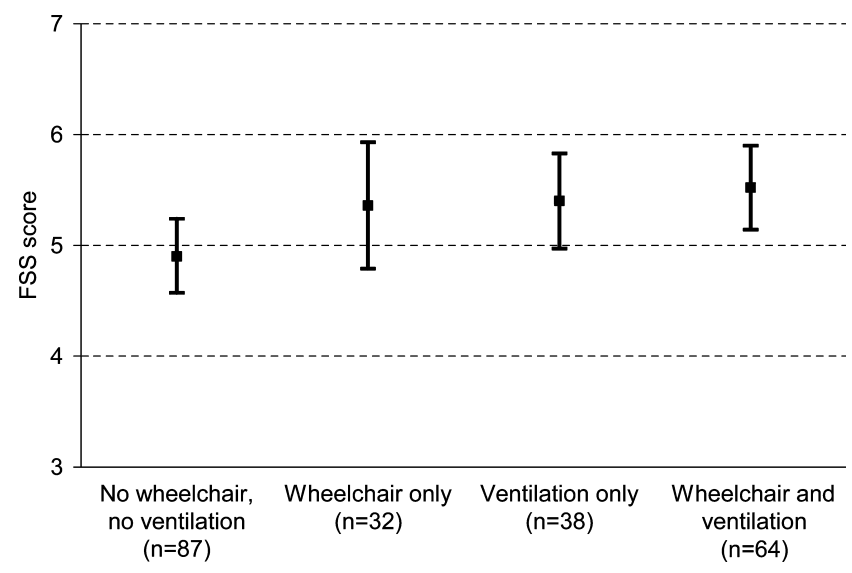

Fig. 2 Mean scores $(95 \% \mathrm{Cl})$ on the Fatigue Severity Scale of adult patients with Pompe disease related to wheelchair use and use of respiratory support

had a FSS score $\geq 4$ and $59 \%$ had a FSS score $\geq 5$. Within the group of patients who used respiratory support, FSS scores were not correlated to the number of hours of ventilation per day $(r=0.06, p=0.57)$. Although the FSS scores differed significantly between patients reporting 'never', 'occasionally' and 'often' sleep disorders, the scores were high in all three groups (mean FSS score 4.8, 5.3 and 5.6, respectively; $\mathrm{p}=0.01)$.

\section{Discussion}

This study shows that fatigue is prevalent in the entire spectrum of mildly and severely affected adult patients with Pompe disease. The FSS scores in this international group of Pompe patients were significantly higher than the scores of healthy controls. Al- 
though we found a significant difference in FSS score between patients with and those without wheelchair or respiratory support, even in the least affected group more than half of the patients had FSS scores $\geq 5$, indicating severe fatigue. FSS scores were not correlated with the duration of disease. The high level of fatigue in our study population, as measured with the FSS, is comparable to that of other chronic disorders such as postpoliomyelitis syndrome (mean score 5.7 , mean age 52 , SD $8, n=65$ ) [17] and multiple sclerosis (mean score 5.3, mean age 45, SD 10, $\mathrm{n}=25)$ [19].

Although all mean FSS scores were high, significant differences existed between patients from different countries. The lowest scores were obtained in the German population. This could not be explained by differences in general characteristics. It is conceivable that the impact of fatigue differs somewhat across countries, since social attitudes, expectations and roles may differ as well [2]. It should also be noted that the German translation of the FSS had not been used before and needs further (cross-cultural) validation. Yet, excellent internal consistency in all languages, as well as good reliability, suggests that the FSS can be a useful tool for assessing fatigue in Pompe disease.

For an optimal treatment of fatigue it is important to know why it is so prominently present in Pompe disease. In a recent review the contribution of 'central' and 'peripheral' components to fatigue in neurological disorders has been discussed [3]. In Pompe disease, a peripheral cause of fatigue, resulting from muscle weakness, is perhaps the most likely explanation. Especially relevant with respect to fatigue in Pompe disease is weakness of the respiratory muscles. Respiratory insufficiency may lead to fragmented sleep, which in turn may lead to daytime sleepiness and fatigue [21]. In the present study, patients who reported 'often' or 'occasionally' sleep disorders were on average more fatigued, but patients who reported to have 'never' sleep difficulties also had high FSS scores. It is possible that fragmented sleep due to respiratory insufficiency has remained unnoted in some of the patients in the latter group, and we and others previously advised that respiratory function should be monitored in all patients with Pompe disease, irrespective of their motor function $[12,25,29]$.
Another possible explanation is the relationship between fatigue and depression $[1,5,8]$. We did not investigate the presence of depression specifically, but found earlier that patients with Pompe disease score equal to the general population on the mental health scale of the SF-36, a health-related quality of life questionnaire [11]. Nevertheless it is recommended to study the possible influence of depression in more detail in future studies, for example by means of the Hospital Anxiety and Depression Scale [33].

Thus, although a peripheral cause of fatigue is probably the most important factor, the underlying mechanisms of fatigue in Pompe disease are in fact not known yet and a possible central contribution should not a priori be excluded in future studies. Noteworthy, in a study with enzyme replacement therapy (ERT) in three patients with moderate to severe late-onset Pompe disease, less fatigue and increased energy was one of the first improvements reported by the patients [30]. This was independent of disease severity and motor response to treatment. It would therefore be interesting to include a standardized measure of fatigue in future clinical trials on the effect of ERT. In multiple sclerosis, Guillain-Barré syndrome and chronic inflammatory demyelinating polyneuropathy adherence to an aerobic training programme resulted in a significant decrease in fatigue and an improvement in physical fitness and quality of life $[10,26]$. Part of the training effect is probably due to increased fitness of the participants and social aspects of the intervention [26], and in this respect it is worthwhile to study the effects of a medically supervised lowintensity training programme on fatigue and general well-being of patients with Pompe disease.

In conclusion, our findings indicate that fatigue is highly prevalent among adult patients with Pompe disease. It is present in both mildly and severely affected patients and is independent of disease duration. The FSS appears a useful tool for the assessment of fatigue in adult patients with Pompe disease. Further research is needed to unravel the pathophysiological mechanism and to identify targets for fatigue management.

Acknowledgements The authors thank the patients and the International Pompe Association for their contribution to the study and Tom de Vries Lentsch for preparing the figures.

\section{References}

1. Bardwell WA, Moore P, Ancoli-Israel S, Dimsdale JE (2003) Fatigue in obstructive sleep apnea: driven by depressive symptoms instead of apnea severity? Am J Psychiatry 160:350-355
2. Buck D, Jacoby A, Baker GA, Ley H, Steen N (1999) Cross-cultural differences in health-related quality of life of people with epilepsy: findings from a European study. Qual Life Res 8:675685
3. Chaudhuri A, Behan PO (2004) Fatigue in neurological disorders. Lancet 363:978-988 
4. Demey HE, Van Meerbeeck JP, Vandewoude MF, Prove AM, Martin JJ, Bossaert LL (1989) Respiratory insufficiency in acid maltase deficiency: the effect of high protein diet. JPEN J Parenter Enteral Nutr 13:321-323

5. Dimeo F, Stieglitz RD, Novelli-Fischer U, Fetscher S, Mertelsmann R, Keul J (1997) Correlation between physical performance and fatigue in cancer patients. Ann Oncol 8:1251-1255

6. Dittner AJ, Wessely SC, Brown RG (2004) The assessment of fatigue. A practical guide for clinicians and researchers. J Psychosom Res 56:157170

7. Engel A, Hirschhorn R (1994) Acid maltase deficiency. In: Engel A, Franzini-Armstrong C (eds) Myology, 2nd ed. McGraw-Hill, New York, pp 1533-1553

8. Flachenecker P, Kumpfel T, Kallmann B, Gottschalk M, Grauer O, Rieckmann P, Trenkwalder C, Toyka KV (2002) Fatigue in multiple sclerosis: a comparison of different rating scales and correlation to clinical parameters. Mult Scler 8:523-526

9. Flachenecker P, Bihler I, Weber F, Gottschalk M, Toyka KV, Rieckmann P (2004) Cytokine mRNA expression in patients with multiple sclerosis and fatigue. Mult Scler 10:165-169

10. Garssen MP, Bussmann JB, Schmitz PI, Zandbergen A, Welter TG, Merkies IS, Stam HJ, Van Doorn PA (2004) Physical training and fatigue, fitness, and quality of life in Guillain-Barre syndrome and CIDP. Neurology 63:23932395

11. Hagemans ML, Janssens AC, Winkel LP, Sieradzan KA, Reuser AJ, Van Doorn PA, Van der Ploeg AT (2004) Late-onset Pompe disease primarily affects quality of life in physical health domains. Neurology 63:16881692

12. Hagemans ML, Winkel LP, Van Doorn PA, Hop WJ, Loonen MC, Reuser AJ, Van der Ploeg AT (2005) Clinical manifestation and natural course of late-onset Pompe's disease in 54 Dutch patients. Brain 128:671-677

13. Hagemans ML, Winkel LP, Hop WC, Reuser AJ, Van Doorn PA, Van der Ploeg AT (2005) Disease severity in children and adults with Pompe disease related to age and disease duration. Neurology 64:2139-2141
14. Hayes W (1988) Statistics, 4th ed. Holt, Rinehart and Winston, Inc., Orlando

15. Herlofson K, Larsen JP (2002) Measuring fatigue in patients with Parkinson's disease-the Fatigue Severity Scale. Eur J Neurol 9:595-600

16. Hirschhorn R, Reuser AJJ (2001) Glycogen storage disease type II; acid $\alpha$ glucosidase (acid maltase) deficiency. In: Scriver CR, Beaudet A, Sly WS, Valle D (eds) The metabolic and molecular bases of inherited disease, 8th ed. McGraw-Hill, New York, pp 3389-3420

17. Horemans HL, Nollet F, Beelen A, Lankhorst GJ (2004) A comparison of 4 questionnaires to measure fatigue in postpoliomyelitis syndrome. Arch Phys Med Rehabil 85:392-398

18. Kleinman L, Zodet MW, Hakim Z, Aledort J, Barker C, Chan K, Krupp L, Revicki D (2000) Psychometric evaluation of the fatigue severity scale for use in chronic hepatitis C. Qual Life Res 9:499-508

19. Krupp LB, LaRocca NG, Muir-Nash J, Steinberg AD (1989) The fatigue severity scale. Application to patients with multiple sclerosis and systemic lupus erythematosus. Arch Neurol 46:1121-1123

20. Matsuishi T, Terasawa K, Yoshida I, Yano E, Yamashita F, Hidaka T, Ishihara O, Yoshino M, Nonaka I, Kurokawa T, Nakamura Y (1982) Vacuolar myopathy with type 2 A fiber atrophy and type $2 \mathrm{~B}$ fiber deficiency. A case of childhood form acid alpha-1,4glucosidase deficiency. Neuropediatrics 13:173-176

21. Mellies U, Stehling F, Dohna-Schwake C, Ragette R, Teschler H, Voit T (2005) Respiratory failure in Pompe disease: treatment with noninvasive ventilation. Neurology 64:1465-1467

22. Merkies IS, Schmitz PI, Samijn JP, van der Meche FG, van Doorn PA (1999) Fatigue in immune-mediated polyneuropathies. European Inflammatory Neuropathy Cause and Treatment (INCAT) Group. Neurology 53:16481654

23. Mobarhan S, Pintozzi RL, Damle P, Friedman H (1990) Treatment of acid maltase deficiency with a diet high in branched-chain amino acids. JPEN J Parenter Enteral Nutr 14:210-212
24. Nunnally JC, Bernstein IH (1994) Psychometric theory, 3rd ed. McGraw-Hill, New York

25. Pellegrini N, Laforet P, Orlikowski D, Pellegrini M, Caillaud C, Eymard B, Raphael J-C, Lofaso F (2005) Respiratory insufficiency and limb muscle weakness in adults with Pompe's disease. Eur Respir J 26:1024-1031

26. Petajan JH, Gappmaier E, White AT, Spencer MK, Mino L, Hicks RW (1996) Impact of aerobic training on fitness and quality of life in multiple sclerosis. Ann Neurol 39:432-441

27. Sivak ED, Ahmad M, Hanson MR, Mitsumoto H, Wilbourn AJ (1987) Respiratory insufficiency in adult-onset acid maltase deficiency. South Med J 80:205-208

28. Van den Hout JMP, Hop W, Van Diggelen OP, Smeitink JA, Smit GP, PollThe BT, Bakker HD, Loonen MC, de Klerk JB, Reuser AJ, Van der Ploeg AT (2003) The natural course of infantile Pompe's disease: 20 original cases compared with 133 cases from the literature. Pediatrics 112:332-340

29. Van der Ploeg AT (2005) Monitoring of pulmonary function in Pompe disease: a muscle disease with new therapeutic perspectives. Eur Respir J 26:984-985

30. Winkel LP, Van den Hout JM, Kamphoven JH, Disseldorp JA, Remmerswaal M, Arts WF, Loonen MCB, Vulto AG, Van Doorn PA, De Jong GD, Hop W, Smit GPA, Shapira SK, Van Diggelen OP, Boer MA, Reuser AJJ, Van der Ploeg AT (2004) Enzyme replacement therapy in lateonset Pompe's disease: a three-year follow-up. Ann Neurol 55:495-502

31. Winkel LPF, Hagemans MLC, van Doorn PA, Loonen MCB, Hop WJC, Reuser AJJ, van der Ploeg AT (2005) The natural course of non-classic Pompe's disease; a review of 225 published cases. J Neurol 252:875-884

32. Wokke JH, Ausems MG, Van den Boogaard MJ, Ippel EF, van Diggelen O, Kroos MA, Boer M, Jennekens FG, Reuser AJ, Ploos van Amstel HK (1995) Genotype-phenotype correlation in adult-onset acid maltase deficiency. Ann Neurol 38:450-454

33. Zigmond AS, Snaith RP (1983) The hospital anxiety and depression scale. Acta Psychiatr Scand 67:361-370 